\title{
PETROGRAFIA E GEOQUÍMICA DO MACIÇO GRANITICO ARROZAL: INTRUSÃO TARDI A PÓS-COLISIONAL ASSOCIADAAO SISTEMA DE CISALHAMENTO DE ALTO ÂNGULO DO VALE DO RIO PARAÍBA DO SUL, SW DO RIO DE JANEIRO
}

\author{
RÔMULO MACHADO ${ }^{1}$, ALEXIS ROSA NUMMER ${ }^{2}$ \& LUIS ANTÔNIO ROSA SEIXAS ${ }^{3}$
}

\begin{abstract}
Resumo O Maciço Arrozal, situado na porção sudoeste do estado do Rio de Janeiro, corresponde a um corpo granítico alongado $(\sim 40 \mathrm{~km} \times 7 \mathrm{Km})$ com características tectônicas tardi- a pós-colisionais, associado com a Zona de Cisalhamento de Alto Ângulo de Além-Paraíba. Apresenta foliação magmática na parte central e no estado sólido em direção às bordas. São caracterizadas três fácies: (i) porfirítica, (ii) foliada e, (iii) leucogranítica. Os minerais essenciais são feldspato potássico (em geral microclínio), plagioclásio, quartzo e biotita; os acessórios são anfibólio, titanita, zircão, apatita, granada, epídoto e minerais opacos, podendo ocorrer carbonato, sericita e mica branca como minerais de alteração. Predominam monzogranitos e localizadamente quartzo monzonitos com granodioritos subordinados. Os teores $\mathrm{em} \mathrm{SiO}_{2}$ variam entre 63,2 a $69,3 \%$, com valores de $\mathrm{K}, \mathrm{O}$ ( $\%$ em peso) entre 3,1 e 4,6\%, correspondendo a série alto K, no diagrama de Le Maître (1985) e razão com $\mathrm{K}_{2} \mathrm{O} / \mathrm{Na}_{2} \mathrm{O}$ entre 0,9 e 1,7. O conteúdo em elementos traço é elevado em $\mathrm{Rb}, \mathrm{Ba}, \mathrm{Zr}$ e Nb, porém moderado em $\mathrm{Sr}$. Estes elementos em diagramas Harker exibem em geral correlação negativa, a qual pode ser atribuida ao efeito de acumulação do plagioclásio e feldspato alcalino acompanhados de zircão \pm ilmenita na fácies leucogranítica (teores elevados em $\mathrm{Sr}, \mathrm{Ba}$ e Zr). Estas rochas superpõem-se ao campo dos granitos tardi a pós-tectônicos no diagrama Zr x ACNK x FMMT.
\end{abstract}

Palavras-chave: Granito Arrozal, Petrografia, Geoquímica

\begin{abstract}
PETROGRAPHY AND GEOCHEMISTRY OF THE ARROZAL GRANITIC MASSIF: LATE AND POST-COLLISIONAL INTRUSION ASSOCIATED TO THE HIGH DIP SHEAR ZONE OF THE SOUTH PARAÍBA VALLEY, SOUTHWESTERN OF RIO DE JANEIRO The Arrozal Massif, situated in the southwestern part of the State of Rio de Janeiro, is an elongated granitic body $(\sim 40 \mathrm{~km} \times 7 \mathrm{Km})$ with late to post-collisional tectonic setting associated with the high-angle shear zone of the Além-Paraíba. It presents magmatic flow in the central part and solid-state foliation toward the border. Three facies are characterized: (i) porphyritic, (ii) foliated and, (iii) leucogranitic. Feldspar, plagioclase, quartz and biotite occur as essencial minerals, whereas amphibole, titanite, zircon, apatite, garnet, epidote, and opaque are acessory phases, occurring also carbonate, sericite, muscovite as alteration minerals. Monzogranites (to quartz monzogranites) are predominant with subordinated granodiorites. $\mathrm{SiO}_{2}$ content varies from 63 to $69 \%$, with values of $\mathrm{K}_{2} \mathrm{O}$ ( $\%$ in weight) from 3,1 and 4,6\% (high- $\mathrm{K}$ series) and $\mathrm{K}_{2} \mathrm{O} / \mathrm{Na}_{2} \mathrm{O}$ ratio from 0,9 and 1,7 . They have high contents of some trace elements ( $\mathrm{Rb}, \mathrm{Ba}, \mathrm{Zr}$ and $\mathrm{Nb}$ ) and moderated for others ( $\mathrm{Sr}$ ). In the Harker diagram, these elements display in general negative correlations that may be ascribed to the effect of the accumulation of plagioclase and alkaline feldspar together with zircon \pm ilmenite in the leucogranitic facies (high content in $\mathrm{Sr}, \mathrm{Ba}$ and $\mathrm{Zr}$ ). These rocks plot in the same diagram Zr x ACNK x FMMT.
\end{abstract}

Palavras-chave: Arrozal Granite, Petrography, Geochemistry

INTRODUÇ̃̃o Os granitos da porção ocidental do domínio do vale do rio Paraíba do Sul no Rio de Janeiro foram classificados inicialmente em três tipos: (1) biotita-granitos (Funil e Resende); (2) biotita-( \pm anfibólio) granitos (São José do Barreiro); (3) biotita-( \pm granada) granitos (Rio Turvo) (Machado \& Peloggia 1987).

Posteriormente, estes granitos foram classificados com base nas estruturas regionais e divididos em dois grupos tectônicos: o dos granitos $\sin -\mathrm{F}_{3}$, relacionados com a terceira fase de deformação regional, e que engloba os dois primeiros tipos, e o dos granitos $\sin -\mathrm{F}_{2}$, relacionados com a segunda fase, e que corresponde ao último tipo. O primeiro grupo, com idade ao redor de $550 \mathrm{Ma}$, foi associado à implantação ou reativação das zonas de cisalhamento de alto ângulo do vale do rio Paraíba do Sul, sendo também classificado como granitos tipo-I Caledoniano, tardi- a pós-colisional, e o segundo grupo, com idade ao redor de $600 \mathrm{Ma}$, foi associado ao desenvolvimento da foliação regional (Machado \& Demange 1991 e 1994). Os granitos sin- $\mathrm{F}_{3}$, classificados também como sin- a tardi- $\mathrm{D}_{3}$, foram designados leucogranitos tipo-I diferenciados, e teriam sido acompanhados do metamorfismo $\mathrm{M}_{2}$ (Heilbron 1995, Heilbron et al. 1995). Os granitos $\sin -\mathrm{F}_{2}$, com granada, muscovita e turmalina, foram classificados como leucogranitos aluminosos tipo-S ou Hercínico e relacionados à fusão parcial de metassedimentos, durante a fase colisional (Machado et al. 1989, Machado \& Demange $1991 \mathrm{e}$ 1994, Heilbron 1993 e 1995, Heilbron et al. 1995). A idade U$\mathrm{Pb}$ em monazita de $576 \pm 6 \mathrm{Ma}$ (Machado et al. 1996, Valladares 1996), obtida no granitóide Rio Turvo, foi considerada como a idade da deformação principal $\left(\mathrm{D}_{1}+\mathrm{D}_{2}\right)$ e do pico metamórfico regional $\left(\mathrm{M}_{1}\right)$ e a idade da fase sincolisional do cinturão no Rio de Janeiro (Heilbron et al. 1996). Em trabalho de revisão e reavaliação dos granitos tipo-S do Rio de Janeiro, Machado \& Dehler (2002) classificam estas rochas como tardi-colisionais. Pereira et al. (2002) consideram a idade Pb-Pb em zircão de 584 $\mathrm{Ma} \pm 6 \mathrm{Ma}$, obtida no granito Funil, como sendo a idade do pico metamórfico regional do cinturão Ribeira na região e ampliam o episódio granítico ligado à fase sincolisional I, para o intervalo de 565 a 605 Ma.

São apresentados e discutidos neste trabalho os dados geoquímicos (elementos maiores e traço) de 28 amostras do Maciço Arrozal ( 5 da fácies porfiritica, 2 da fácies leucogranítica, 19 da fácies foliada e 2 de enclave), 2 amostras do Maciço Getu- 
lândia e 1 da rocha encaixante (Ortognaisses da Unidade Quirino). Enfatiza-se no trabalho a comparação geoquímica entre as amostras deformadas e não deformadas do Maciço Arrozal, assim como a sua comparação com a de um maciço similar (Maciço Getulândia), já estudado anteriormente (Valladares 1996), e com uma amostra da rocha encaixante.

CONTEXTO REGIONAL DOS GRANITOS São disponíveis na literatura poucos trabalhos de integração regional e de classificação dos diferentes tipos de granitos do cinturão Paraíba do Sul no estado do Rio de Janeiro (Machado \& Peloggia 1987, Machado \& Demange 1994, Heilbron 1995, Heilbron et al. 1995, Machado 1997, Junho 1998).

Por outro lado, existe um número muito expressivo de trabalhos envolvendo especialmente os granitos pós-tectônicos do domínio serrano do referido estado, regiões de Petrópolis e Teresópolis, e nos arredores da cidade do Rio de Janeiro (ver sínteses em Machado \& Demange 1984, Penha 1984, Machado 1997, Junho 1993 e 1998).

Coube a Machado \& Peloggia (1987) a realização do primeiro trabalho de integração e síntese regional dos granitos do estado do Rio de Janeiro. Nele é apresentada uma proposta de classificação dos granitos com base nas informações mineralógicas, petrográficas e cartográficas então disponíveis, segundo sua distribuição em três domínios regionais: Vale do Paraíba do Sul, Serra dos Órgãos e Litorâneo.

A partir do início da década de 90 surgem os primeiros trabalhos sobre os granitos do estado que consideram na sua classificação as estruturas tectônicas regionais. Assim, os granitos brasilianos foram inicialmente divididos em três grupos tectônicos, denominados - do mais antigo para o mais novo - de: $\sin -\mathrm{F}_{2}$, $\sin -\mathrm{F}_{3}$ e sin- $\mathrm{F}_{4}$ (Machado \& Demange 1991, 1992 e 1994).

Nos granitos sin- $\mathrm{F}_{2}$ foram englobados os maciços afetados pela deformação regional, sendo portanto foliados e exibem uma foliação mais intensa nas bordas, onde são freqüentes estruturas gnáissicas e miloníticas. Estes granitos foram divididos, em função do nível metamórfico de colocação, em quatro grupos: (1) em fácies granulito (Bela Joana), (2) transição fácies granulito-anfibolito (Niterói), (3) em fácies anfibolito inferior (Serra das Araras, Rio Turvo) e, (4) em fácies anfibolito superior (Serra dos Órgãos) (Machado \& Demange 1994).

Os granitos $\sin -\mathrm{F}_{3}$ foram considerados posteriores à foliação regional, havendo um amplo desenvolvimento no vale do rio Paraiba do Sul, onde se associam notadamente às zonas de cisalhamento de alto ângulo regionais, ocorrendo como corpos alongados e foliados, com preservação de estruturas magmáticas na parte central e deformacional nas bordas. Foram aí englobados os granitos Vassouras, Getulândia, Fortaleza, Arrozal, Varre-Sai, Anta, Parati e Parati-Mirim, Funil, Resende e outros (Machado \& Demange 1994, Machado 1997).

Nos granitos sin-F4 foram englobados os corpos desvinculados da estruturação regional NE-SW do cinturão, e que apresentam maior incidência no domínio serrano do estado e nos arredores da cidade do Rio de Janeiro. São stocks subarredondados (diâmetro médio de $10 \mathrm{Km}$ ), não deformados, com estrutura de fluxo restrita às bordas, e composição monzogranítica a álcalifeldspato-granítica. Foram aqui incluídos os granitos Sana, São Pedro, Nova Friburgo, Surui, Andorinha, Utinga, Mangaratiba, Mambucaba, dentre outros.

Ainda nesta mesma linha de classificação, Heilbron (1995) e Heilbron et al. (1995) dividem os granitos do Rio de Janeiro em quatro grupos: (1) grupo contemporâneo à deformação principal $\left(D_{1}+D_{2}\right)$ e à primeira fase de metamorfismo $\left(M_{1}\right),(2)$ grupo tardio à deformação principal, (3) grupo sin- a tardi- $\mathrm{D}_{3}$, e contemporâneo à segunda fase de metamorfismo $\left(\mathrm{M}_{2}\right) \mathrm{e},(4)$ grupo pós-tectônico. Dentro destes grupos, separou-se cinco tipos de granitos, designando-os, do mais antigo para o mais novo, de: $\gamma 1$ e $\gamma 2$ (grupo 1), $\gamma 3$ (grupo 2), $\gamma 4$ (grupo 3), $\gamma 5$ (grupo 4).

No primeiro tipo são incluídos o batólito Serra dos Órgãos e os gnaisses facoidais; no segundo, os maciços Rio Turvo, Serra da Concórdia, granada charnockitóides e Juiz de Fora, granitóide Matias Barbosa e leucogranitos tipo-S, estes últimos intrusivos no Grupo Andrelândia; no terceiro, os granitos Serra do Lagarto e Taquaral; no quarto, leucogranitos tipo-I diferenciados, Serra do Ipiranga ou Vassouras, Getulândia, Fortaleza, Araras e Pedra Branca; no quarto tipo, os granitos Favela, Nova Friburgo, Sana, Teresópolis e Caju.

Recentemente, em trabalho de revisão e reavaliação dos granitos tipo-S do Rio de Janeiro, Machado \& Dehler (2002) consideraram estes granitos como relacionados a um ambiente tectônico tardi-colisional, e gerados sob condições de uma crosta espessada. A colocação desses corpos teria sido controlada por zonas de cisalhamento dúcteis de alto e baixo ângulo.

MACIÇO GRANÍTICO ARROZAL O Maciço Arrozal corresponde a um corpo granítico alongado na direção ENEWSW, que ocorre na porção sudoeste do estado Rio de Janeiro (Fig 1 A). Possui cerca de $40 \mathrm{~km}$ de extensão por $7 \mathrm{~km}$ de largura e associa-se ao Sistema de Cisalhamento Dúctil de Alto Ângulo de Além-Paraíba. O corpo apresenta foliação magmática na parte central e foliação com deformação no estado sólido em direção às bordas. Os contatos são tectônicos com as rochas encaixantes, sendo marcados pelo desenvolvimento expressivo de rochas miloníticas e protomiloníticas.

O maciço apresenta características tectônicas de granitos tardi-colisionais, reforçando assim as classificações anteriores propostas para o mesmo (Machado \& Demange 1994, Machado 1997, Nummer 2001). Embora não existam datações neste maciço, acredita-se que sua idade seja muito próxima daquela obtida em granitos similares, como o Getulândia, por exemplo, onde duas idades U-Pb em monazita indicaram valores de 532 e $538 \mathrm{Ma}$ (Machado et al. 1996, Valladares 1996).

Petrografia O Maciço Granítico Arrozal é constituído de três faciologias principais: (i) fácies porfirítica (central), (ii) fácies foliada (de borda) e, (iii) fácies leucogranítica (Nummer 2001) (Fig. 1B). Há um predomínio da fácies foliada, aparecendo a fácies leucogranítica como subordinada. Cabe salientar que, na fácies foliada, associam-se porções mais deformadas, com a rocha assumindo muitas vezes aspecto gnáissico e protomilonítico. Contudo, muitas das amostras em lâmina delgada não exibem deformação em estado sólido.

A fácies porfiritica ocupa sobretudo a parte central do maciço e caracteriza-se por uma granulação média a grossa, textura inequigranular a levemente porfiritica, com fenocristais $(0,5$ a 2,0 cm) de feldspato potássico e plagioclásio, que perfazem conjuntamente de 5 a $15 \%$ do volume da rocha. Os minerais essenciais são microclínio, plagioclásio, quartzo e biotita; os acessórios são granada, epidoto, zircão, apatita e minerais opacos, ocorrendo ainda carbonato, sericita e mica branca como minerais de alteração.

A fácies foliada representa mais de $2 / 3$ da área do maciço e é encontrada principalmente nas bordas do mesmo. Esta faciologia apresenta com freqüência uma pronunciada estrutura bandada, caracterizada por leitos centimétricos melanocráticos ricos em biotita, associado muitas vezes com hornblenda, que se alternam com leitos leucocráticos ricos em quartzo e feldspato.

Nesta fácies são encontradas rochas com texturas protomilonítica, milonítica, milonito-gnaisse (sensu Higgins 1971) e filonítica, neste último caso associadas invariavelmente com rochas metassedimentares que ocorrem intercaladas na parte sul do maciço. Nestas rochas são comuns cristais de quartzo com extinção 


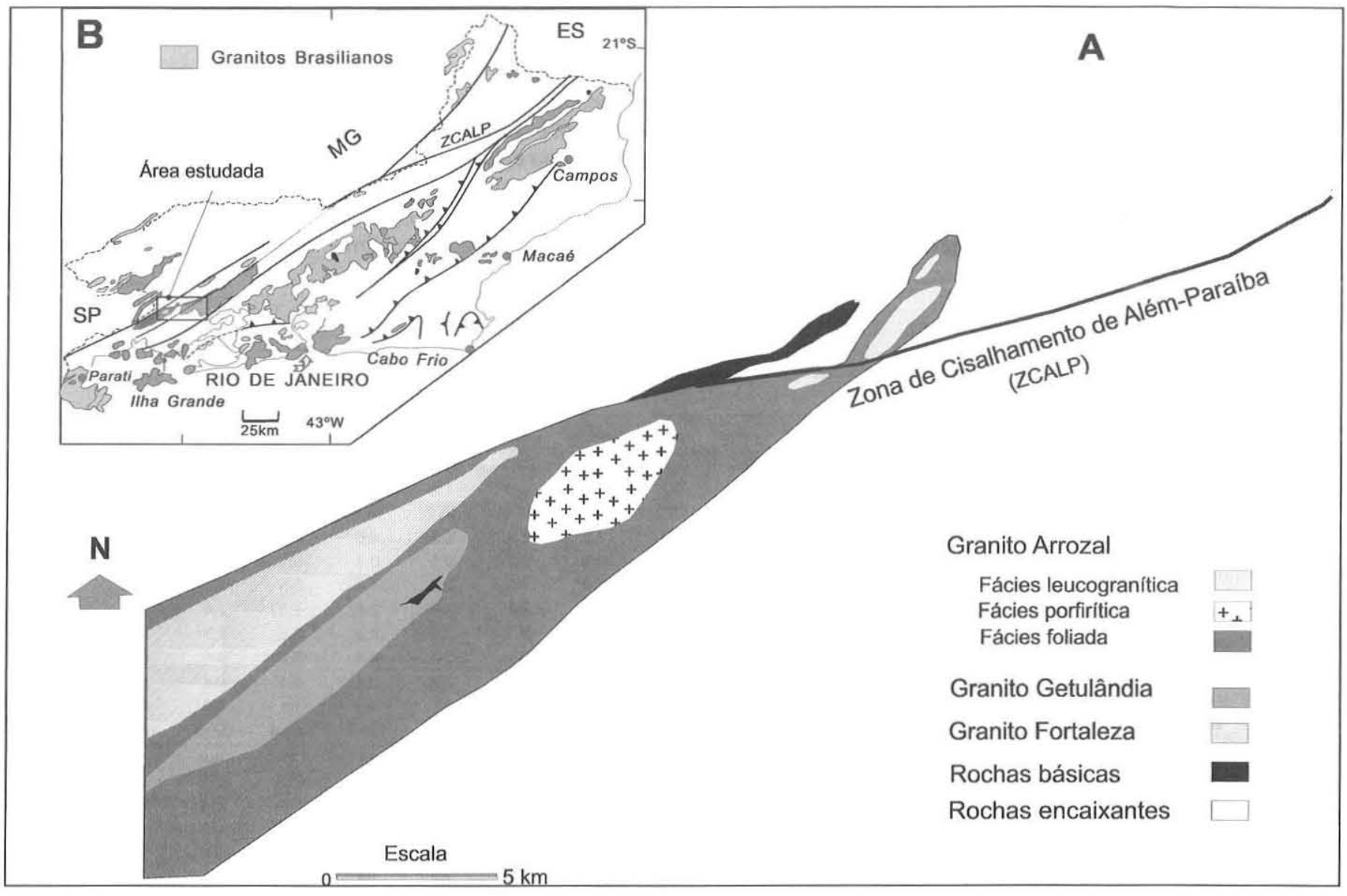

Figura 1. Mapa de localização da área investigada (A) e mapa de divisão de fácies do Maciço Arrozal (B).

ondulante e recuperação de grãos, assim como formação de fitas e ribbons de quartzo, que realçam a orientação da rocha.

A fácies leucogranítica ocorre na parte centro-norte do maciço e corresponde a um pequeno corpo alongado $(2,8 \times 0,4 \mathrm{~km})$ que ocupa menos da $10 \%$ de sua área de exposição. São rochas leucocráticas, de granulação média a grossa, inequigranulares e porfiríticas, rosadas e esbranquiçadas, podendo conter enclaves microgranulares decimétricos, dioríticos a quartzo dioríticos.

Os minerais essenciais são plagioclásio, quartzo e ortoclásio; os acessórios são biotita, granada e minerais opacos, ocorrendo ainda hornblenda, titanita, zircão e epídoto.

Geoquímica Foram selecionadas 31 amostras para análise de rochas total (maiores e traço), sendo 27 amostras do Maciço Arrozal (2 da fácies leucogranítica, 5 da fácies porfirítica, 19 da fácies foliada e 1 de enclave microgranular), 3 do Maciço Getulândia ( 2 de granito equigranular grosso e 1 de enclave microgranular) e 1 da rocha encaixante (Ortognaisses da Unidade Quirino).

As amostras do Maciço Arrozal classificam-se no diagrama QAP de Streckeisen (1976) como monzogranitos (fácies porfirítica), monzogranitos a granodioritos (fácies deformada) e quartzo monzonitos a monzogranitos (fácies leucogranítica) e quartzo monzodioritos (enclaves) (Fig. 2).

As amostras do Maciço Getulândia e da rocha encaixante (Unidade Quirino) classificam-se neste mesmo diagrama como monzogranitos. Na maioria dos diagramas apresentados utilizouse a $\mathrm{SiO}_{2}$ como índice de diferenciação. Embora tenham sido confeccionados vários diagramas, onde foram testados outros elementos (maiores e traço), optou-se aqui por apresentar os diagramas que são efetivamente importantes na discussão sobre

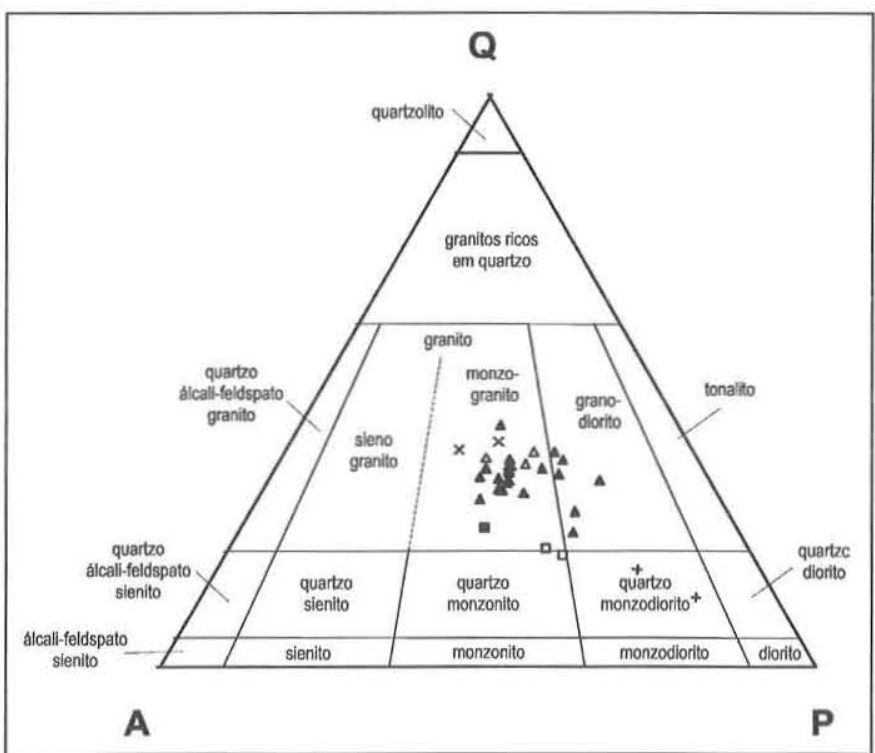

Figura 2. Classificação das amostras estudadas segundo o diagrama QAP de Streckeisen (1976). Granito Arrozal: fácies foliada (triângulo cheio), fácies porfiritica (triângulo vazado), fácies leucogranítica (quadrado vazado) e enclaves microgranulares (cruzes); Granito Getulândia (x).

a cristalização dos minerais. Além disso, foi efetuado um tratamento geoquímico individualizado das fácies porfirítica e deformada do Maciço Arrozal, visando desta forma avaliar possíveis 
modificações químicas decorrentes da deformação.

Fácies porfiritica e leucogranitica A fácies porfirítica, caracterizada pelo predomínio de estruturas magmáticas, inclui cinco amostras (ARP 39, ARP 46, ARP 49, ARP 98 e ARP 106) oriundas da porção central do maciço, onde a composição dominante é monzogranítica, enquanto a fácies leucogranítica inclui duas amostras (ARL 47 e ARL 227) classificadas como quartzo monzonito a monzogranito.

O comportamento geoquímico (elementos maiores e traço) destas amostras, com base em diagramas de variação, é discutido a seguir.

Os teores de $\mathrm{SiO}_{2}$ das amostras de ambas as faciologias variam entre 63,2 a $69,3 \%$, com valores de $\mathrm{K}_{2} \mathrm{O}$ (\% em peso) entre 3,1 e $4,6 \%$ e razão $\mathrm{K}_{2} \mathrm{O} / \mathrm{Na}_{2} \mathrm{O}$ entre 0,9 e 1,7 (Tabela 1). $\mathrm{Na}$ comparação entre as duas faciologias, nota-se que a fácies porfirítica apresenta valores mais elevados em $\mathrm{SiO}_{2}$ e razão $\mathrm{K}_{2} \mathrm{O}$ / $\mathrm{Na}_{2} \mathrm{O}$ mais baixa, sugerindo assim tratar-se de uma faciologia mais evoluída, o que também é indicado pela sua composição

Tabela 1: Dados geoquímicos dos Granitos Arrozal e Getulândia e ortognaisse encaixante.

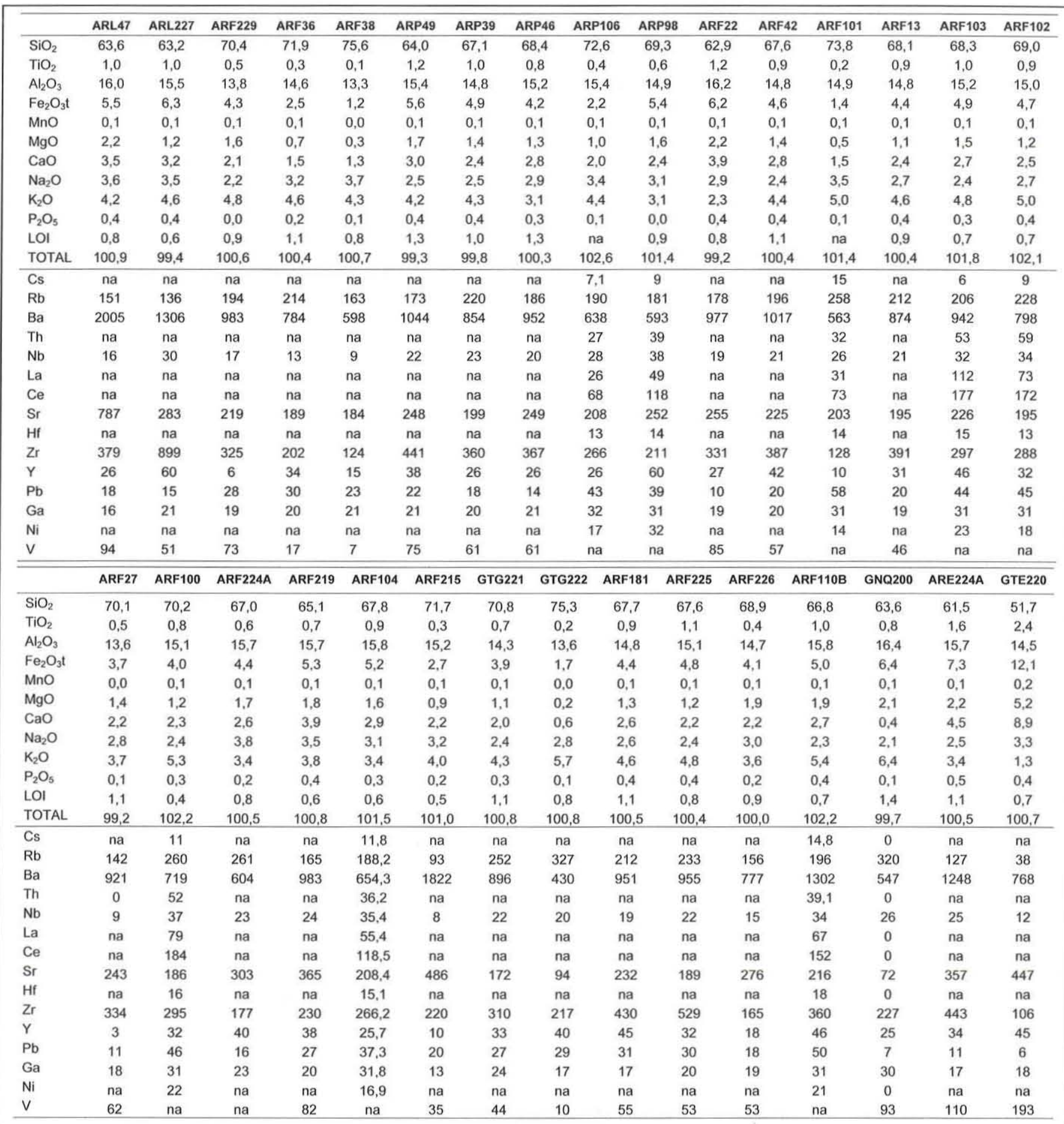

Legenda: Granito Arrozal - fácies leucogranítica (ARL), fácies porfirítica (ARP), fácies foliada (ARF) e enclave microgranular (ARE); Granito Getulândia - fácies equigranular (GTG) e enclave microgranular (GTE); Gnaisse Quirino (GNQ) 
mineralógica.

O conteúdo em elementos traço destas faciologias é elevado em Rb (136 a 220 ppm), Ba (2005 a 593 ppm), Zr (899 a 211 ppm) e $\mathrm{Nb}$ (16 a 38 ppm); e moderado em Sr (787 a 199 ppm) (Tabela 1). A fácies porfirítica exibe teores mais elevados em $\mathrm{Rb}$, mais baixos em $\mathrm{K}_{2} \mathrm{O}, \mathrm{Ba}, \mathrm{Zr}$ e $\mathrm{Sr}$, e equivalentes em $\mathrm{Nb}$, confirmando deste modo o seu caráter mais evoluído.

Os valores em Rb são compatíveis com o intervalo de valores obtidos para os granitos félsicos não fracionados (entre 200 e 250 ppm, 64 amostras do tipo-I e 119 do tipo-S) do cinturão Lachlan na Austrália (Chappell \& White 1992).
O predomínio de plagioclásio em relação ao feldspato potássico na fácies leucogranítica reflete-se por razões $\mathrm{Rb} / \mathrm{Sr}<0,5$, enquanto a fácies porfirítica (com fenocristais de feldspato potássico + biotita) apresenta razões $\mathrm{Rb} / \mathrm{Sr}>0,7$, com máximo de 1,1 .

$\mathrm{O}$ índice de saturação em alumina $(\mathrm{A} / \mathrm{CNK})$ do conjunto de amostras estudadas é próximo a 1,0 (Fig. 3A), com um grupo delas situando-se no campo metaluminoso (fácies leucogranítica, $\mathrm{A} / \mathrm{CNK} \sim 0,9$ ) e outro no campo marginalmente peraluminoso (fácies porfirítica, $1,1<\mathrm{A} / \mathrm{CNK}<1,2$ ), segundo o diagrama de Maniar \& Piccoli (1989). Os primeiros valores situam-se no intervalo de $\mathrm{A} / \mathrm{CNK}$ (entre 0,9 e 1,1 ) definido por Chappell
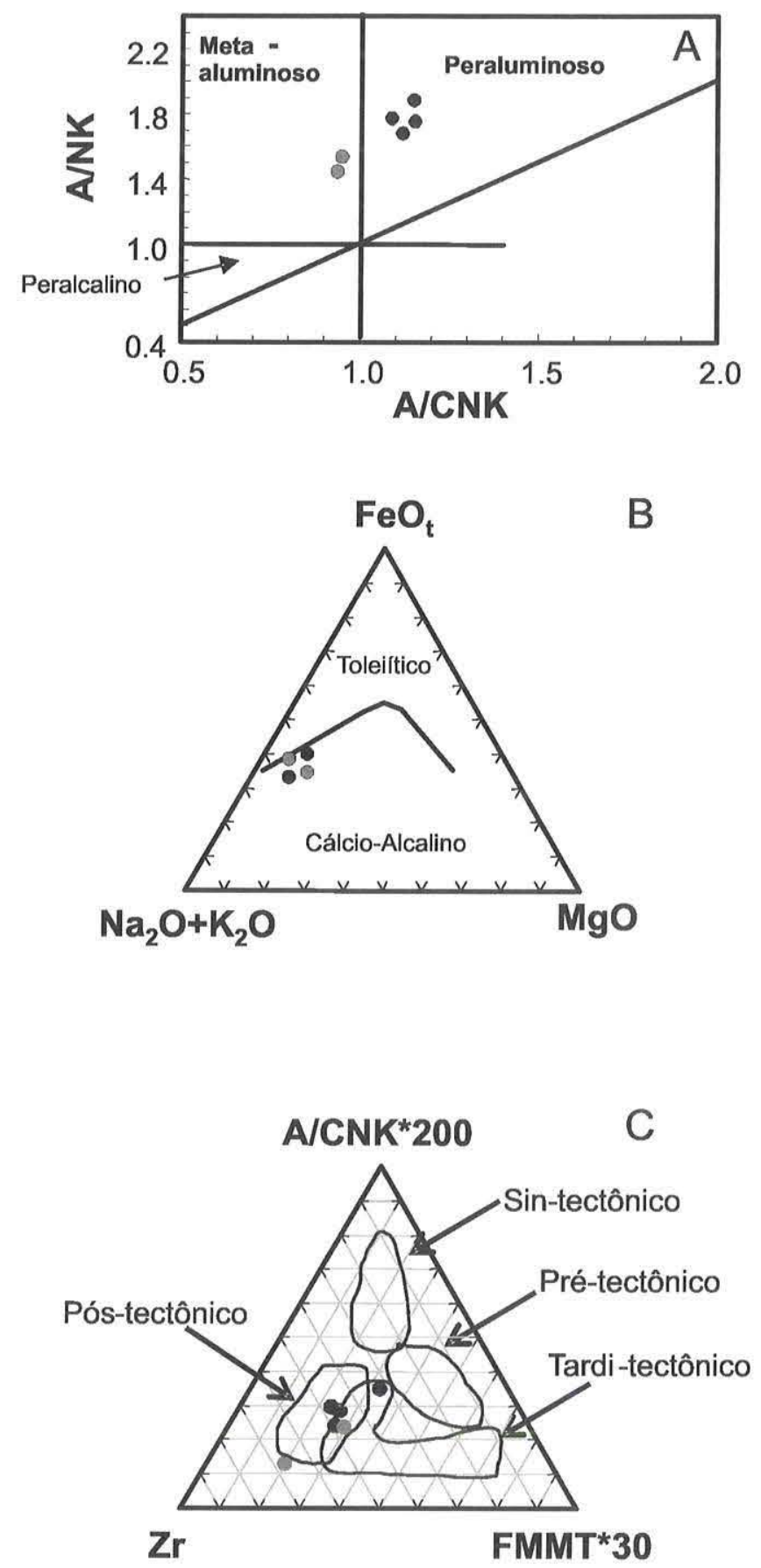

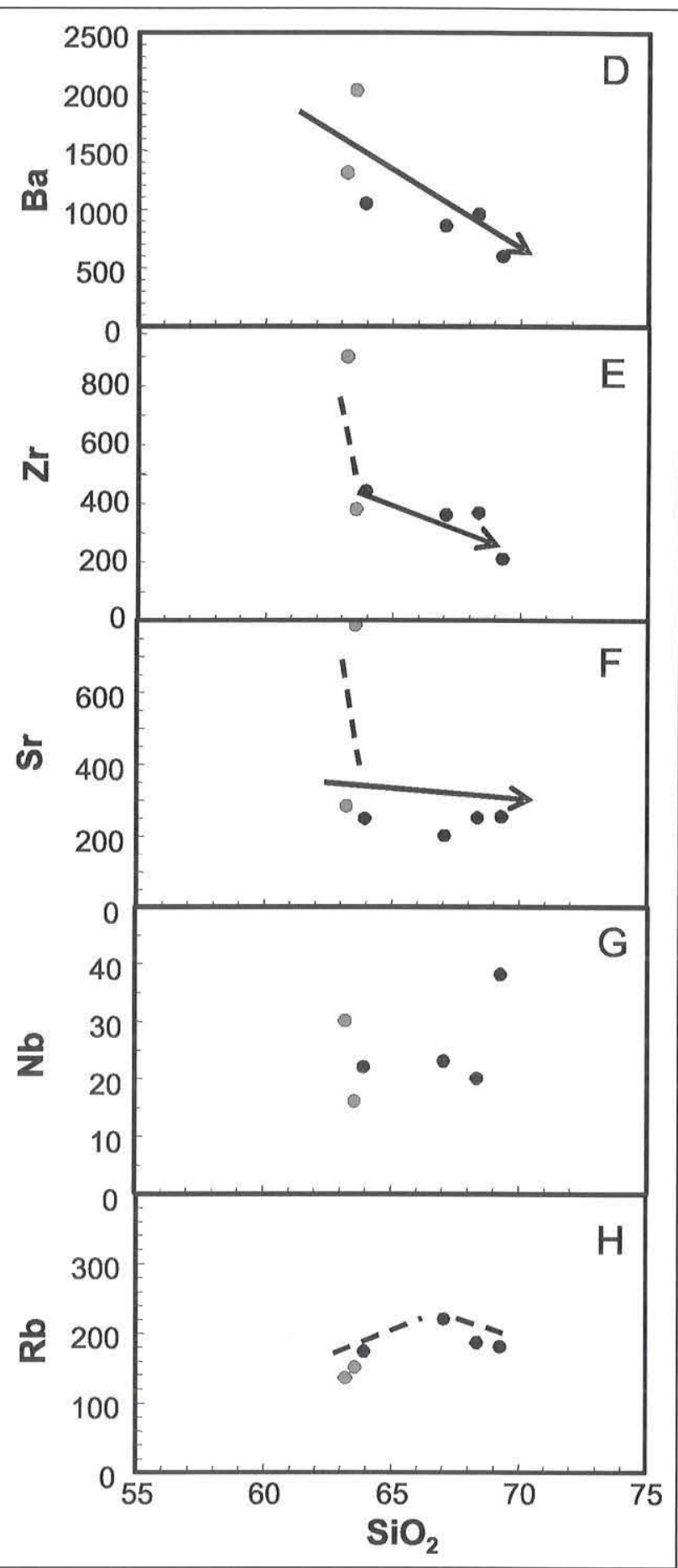

Figura 3. Diagramas de caracterização geoquímica e de Harker para as fácies porfirítica (círculo preto) e leucogranitica (círculo cinza) do Maciço Arrozal: A- índice de saturação em alumina; B - AFM; C-índice de saturação em alumina vs. Zr vs. FMMT $\left(\mathrm{Fe}_{2} \mathrm{O}_{3} t+\mathrm{MnO}+\mathrm{MgO}+\mathrm{TiO}_{2}\right) ; \mathrm{D}, \mathrm{E}, \mathrm{F}$, G e H-diagramas de $\mathrm{SiO} 2$ vs. $\mathrm{Ba}, \mathrm{Zr}$; $\mathrm{Sr}$; $\mathrm{Nb}$ e Rb (tendências indicadas por flechas). 
\& White (1992) para os granitos tipo-I do cinturão Lachlan na Austrália, enquanto os últimos situam-se no intervalo de superposição dos granitos tipo-I e S (entre 1,1 e 1,4).

A relação $\mathrm{FeOt} / \mathrm{FeOt}+\mathrm{MgO}$ da fácies leucogranítica varia de 0,73 a 0,56 , sendo estes valores explicados pela presença de minerais ferromagnesianos contendo assembléias com proporções variáveis de piroxênio (hedenbergita encontrada como relícto) + Fe-hornblenda + biotita. $\mathrm{Na}$ fácies porfirítica, esta relação é mais ou menos constante, com valores ao redor de 0,63 , os quais podem ser explicados pela presença de minerais máficos como Fe-hornblenda + biotita.

No diagrama AFM, de Irvine \& Baragar (1971), as amostras estudadas ocupam o campo das rochas cálcio-alcalinas (Fig. 3B). O teor em $\mathrm{K}_{2} \mathrm{O}$ situa-se no campo das séries magmáticas alto-K, segundo o diagrama de Le Maître (1985).O conteúdo elevado em elementos traço ( $\mathrm{Rb}, \mathrm{Ba}, \mathrm{Zr}$ e $\mathrm{Nb}$ ) reafirma o caráter potássico destas rochas (Figs. 3D-H). Nota-se que estes elementos em diagramas Harker exibem em geral uma correlação negativa, a qual é menos evidente para o Sr. Esta correlação negativa dos elementos pode ser explicada como resultado da acumulação de plagioclásio e feldspato alcalino acompanhados de zircão \pm ilmenita na fácies leucogranítica (refletidos pelos altos picos em Ba, Zr, Sr, das amostras ARL 47 e ARL 227, Tabela 1 e Figs. 3D a F).

$\mathrm{O}$ efeito cumulativo do plagioclásio nesta faciologia é mais efetivo na primeira amostra (ARL 47) do que na segunda (ARL 227), conforme pode ser observado nos teores mais elevados em $\mathrm{CaO}(3,5 \%$, contra $3,2 \%), \mathrm{Sr}$ (787 ppm, contra $283 \mathrm{ppm}), \mathrm{Ba}$ (2005 ppm, contra $1306 \mathrm{ppm})$ e $\mathrm{Al}_{2} \mathrm{O}_{3}(16,0 \%$, contra 15,5\%), e mais baixos em $\mathrm{K}_{2} \mathrm{O}(4,2 \%$, contra $4,6 \%)$. O Rb, ao contrário destes elementos, apresenta uma leve correlação positiva.

Nas amostras da fácies porfirítica parece ter havido uma participação mais importante da biotita, conforme sugerido pela tendência levemente positiva do Rb durante a diferenciação e sendo isto desvinculado do comportamento observado para o $\mathrm{Ba}$. A mudança no comportamento do $\mathrm{Rb}$ com a $\mathrm{SiO}_{2}$, ao redor de $67 \%$, deve traduzir uma cristalização mais efetiva do feldspato potássico e biotita a partir desse momento (Fig. 3H). Isto também é observado na curva de comportamento do $\mathrm{K}_{2} \mathrm{O}$ (Fig. 5E).
No diagrama triangular $\mathrm{Zr} \times \mathrm{ACNK}^{*} 200 \times \mathrm{FMMT} * 30$, utilizado por Bilal et al. (2000), para caracterização tectônica das suítes graníticas neoproterozóicas da Província Mantiqueira nos estados de Minas Gerais e Espírito Santo, as amostras de ambas as faciologias ocupam o campo dos granitos tardi e pós-tectôni$\cos$ (Fig. 3C).

Nos diagramas clássicos de discriminação de ambientes tectônicos, as amostras da fácies porfirítica distribuem-se nos campos de granitos pré- a sincolisionais (Batchelor \& Bowden 1985), e entre arco vulcânico a intra-placa (Pearce et al. 1984), enquanto as amostras da fácies leucogranítica distribuem-se nos campos de granitos pós-colisionais e tardi-orogênicos, e no campo intra-placa (Figs. 4 A e B).

Fácies foliada Esta fácies distribui-se ao redor das fácies porfirítica e leucogranítica do Maciço Arrozal, com as amostras analisadas distribuindo-se em quatro setores do referido maciço, assim denominados: NE, NW, SW e SE. Esta subdivisão foi efetuada com o objetivo de avaliar possíveis influências das rochas encaixantes no quimismo do Maciço Arrozal durante os processos de deformação e de circulação de fluídos. Deste modo, os setores acima são constituídos da seguintes amostras:

- Setor NE - inclui três amostras de monzogranitos a granodioritos, sendo duas delas intensamente deformadas (ARF36 e ARF38) e mais evoluídas ( $\mathrm{SiO}, 72$ a $76 \%$ ), e uma menos deformada e menos evoluída (ÂRF 229, com 70,4\% de $\left.\mathrm{SiO}_{2}\right)$;

- Setor NW (entre a fácies porfirítica e o Domínio Quirino) - inclui um grupo de oito amostras (ARF 22, ARF 42, ARF 13, ARF 102, ARF 27, ARF 100, ARF 101 e ARF 103), as quais gradam lateralmente para a fácies porfirítica. Seus teores em $\mathrm{SiO}_{2}$ variam de 62,9 a $73,8 \%$;

- Setor SW (entre a fácies porfirítica e o Maciço Getulândia) - as três amostras deste setor (ARF 104, ARF 215, ARF 219) possuem teores em $\mathrm{SiO}_{2}$ entre 65,1 a $71,7 \%$;

- Setor SE (entre a fácies porfirítica e o Domínio Serra das
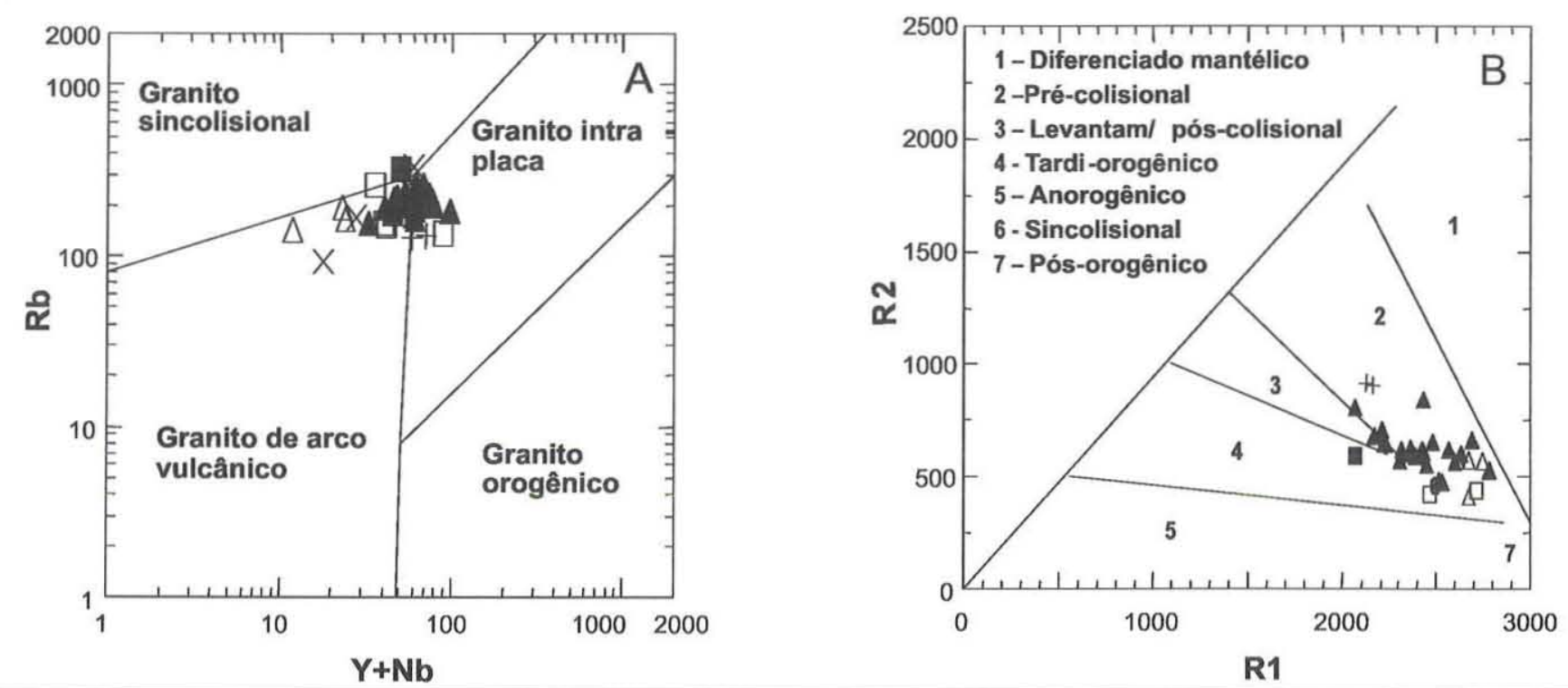

Figura 4. Diagramas de discriminação de ambientes tectônicos de Pearce et al. (1984) e Batchelor \& Bowden (1985) para amostras dos Granitos Arrozal e Getulândia (mesma simbologia da Fig. 2) e gnaisses encaixantes (quadrado cheio): A - Y $+N b$ vs. Rb; $B-R, v s . R_{2}$ 
Araras) - neste setor, mais heterogêneo, predominam "protomilonitos" intercalados com rochas graníticas e básicas. Foram analisadas cinco amostras desta faciologia (ARF 110B, ARF 181, ARF 224A, ARF 225, ARF 226), cujos teores em $\mathrm{SiO}_{2}$ variam entre 66,8 a $73,4 \%$.

A fácies deformada, litologicamente mais heterogênea do que as faciologias anteriores, classifica-se no diagrama QAP de Streckeisen (1976) como granodiorito a monzogranito (Fig. 2)

O comportamento geoquímico para um conjunto de diagramas selecionados está representado na Figura 5. As tendências observadas nesses diagramas podem ser sumarizadas da seguinte maneira:

- a manutenção do índice de saturação em alumina (A/CNK) em torno de 1,1 (entre 1,0 e 1,2) (Fig. 5A). No diagrama de Maniar \& Picolli (1989) observa-se que as amostras da fácies foliada superpõem-se em grande parte com as amos- tras da fácies porfirítica, caracterizando-se igualmente como magmatismo marginalmente peraluminoso (Fig. 5B).

- os diagramas de variação de $\mathrm{CaO}$ e o índice FMMT $\left(\mathrm{Fe}_{2} \mathrm{O}_{3} \mathrm{t}+\mathrm{MnO}+\mathrm{MgO}+\mathrm{TiO}_{2}\right)$, em função da $\mathrm{SiO}_{2}$ (Figs. $5 \mathrm{C}$ e D), apresentam correlação negativa, sugerindo que a fácies foliada guarda evidências de processos de diferenciação magmática da mesma forma como foi identificada para a fácies porfirítica.

- o $\mathrm{K}_{2} \mathrm{O}$, apesar da relativa dispersão das amostras, apresenta tendência geral de correlação positiva com $\mathrm{a} \mathrm{SiO}_{2}$ até teores ao redor de $70 \%$, havendo a partir daqui uma certa estabilização deste elemento nos termos mais evoluídos, como provável reflexo da cristalização do feldspato alcalino e biotita (Fig. 5C). Observa-se ainda que esta tendência é marcada por uma dispersão maior de dados ao longo de duas linhas paralelas de aumento de $\mathrm{K}_{2} \mathrm{O}$, que se repetem de maneira similar com o aumento da razão $\mathrm{K}_{2} \mathrm{O} / \mathrm{Na}_{2} \mathrm{O}$ (Fig. 5F). Isto
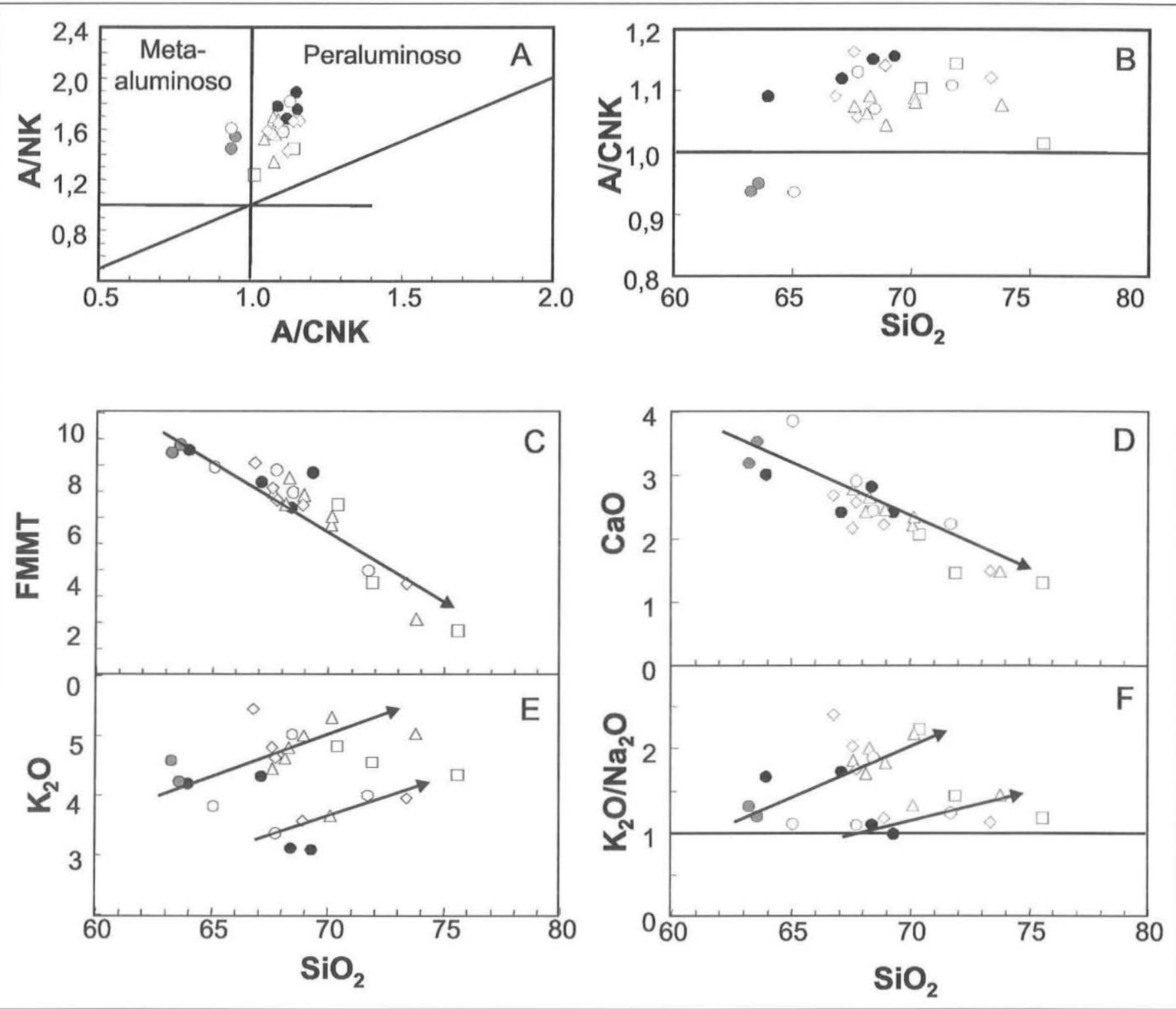

Figura 5. Diagramas de caracterização geoquímica e de Harker das diferentes fácies do Maciço Arrozal. Símbolos vazios: fácies foliada NE (quadrado), NW (triângulo), SE (losângulo) e SW (circulo); fácies porfiritica (círculo preto) e leucogranitica (círculo cinza). A e B-indice de saturação em alumina; $\mathrm{C}, \mathrm{D}, \mathrm{E}$ e $\mathrm{F}$ - diagramas de $\mathrm{SiO}_{2}$ vs. $\mathrm{FMMT}\left(\mathrm{Fe}_{2} \mathrm{O}_{3} t+\mathrm{MnO}+\mathrm{MgO}+\mathrm{TiO}_{2}\right), \mathrm{K}_{2} \mathrm{O}$, $\mathrm{Ca}$ e $\mathrm{K}_{2} \mathrm{O} / \mathrm{Na}_{2} \mathrm{O}$ (tendencias indicadas por flechas). 
pode ser explicado de duas formas: a) presença em maior ou menor proporção de fenocristais de feldspato alcalino; e b) efeito da sobreposição do processo de deformação milonítica que tende a produzir rochas mais enriquecidas em $\mathrm{SiO}_{2} \mathrm{e}$, portanto, causar um efeito de diluição dos álcalis.

-as tendências gerais exibidas pelos elementos maiores se repetem para os elementos traço selecionados. Nas Figuras 6A a 6D, foram construídos os diagramas de Harker para $\mathrm{Ba}, \mathrm{Sr}, \mathrm{Zr}$ e $\mathrm{Rb}$. Esses diagramas confirmam a tendência de evolução magmática observada em ambas as faciologias. Esta evolução é compatível com a diminuição progressiva de $\mathrm{Ba}, \mathrm{Sr}$ e $\mathrm{Zr}$, acompanhada por um ligeiro aumento do $\mathrm{Rb}$. Isto é confirmado pela correlação positiva apresentada pelo diagrama de $\mathrm{Zr}$ vs. Ba, denotando a maior participação de zircão e feldspatos desde os termos menos evoluídos ( $\sim 63 \%$ em $\left.\mathrm{SiO}_{2}\right)$ até os mais evoluídos ( 73\% em $\left.\mathrm{SiO}_{2}\right)$.

- a comparação entre os setores acima evidencia comportamento similar para o conjunto de elementos nos diferentes diagramas selecionados, com exceção das amostras do setor $\mathrm{SW}$, que apresentam acentuada dispersão. $\mathrm{O}$ comportamento anômalo da amostra ARF 215, com elevados teores em Ba (1822 ppm), $\mathrm{Sr}(486 \mathrm{ppm})$ e relativamente em $\mathrm{Al}_{2} \mathrm{O}_{3}$, baixos em $\mathrm{Rb}(93$ ppm) e na razão $\mathrm{Rb} / \mathrm{Sr}(0,2$, contra 0,5 a 1,2 , nas demais amostras deste setor), sugere interação com fase fluída, que teria promovido a cristalização de feldspato alcalino (microclínio) na matriz do Maciço Getulândia ou a geração segunda de biotita (alterada hidrotermalmente) com características composicionais mais magnesianas.

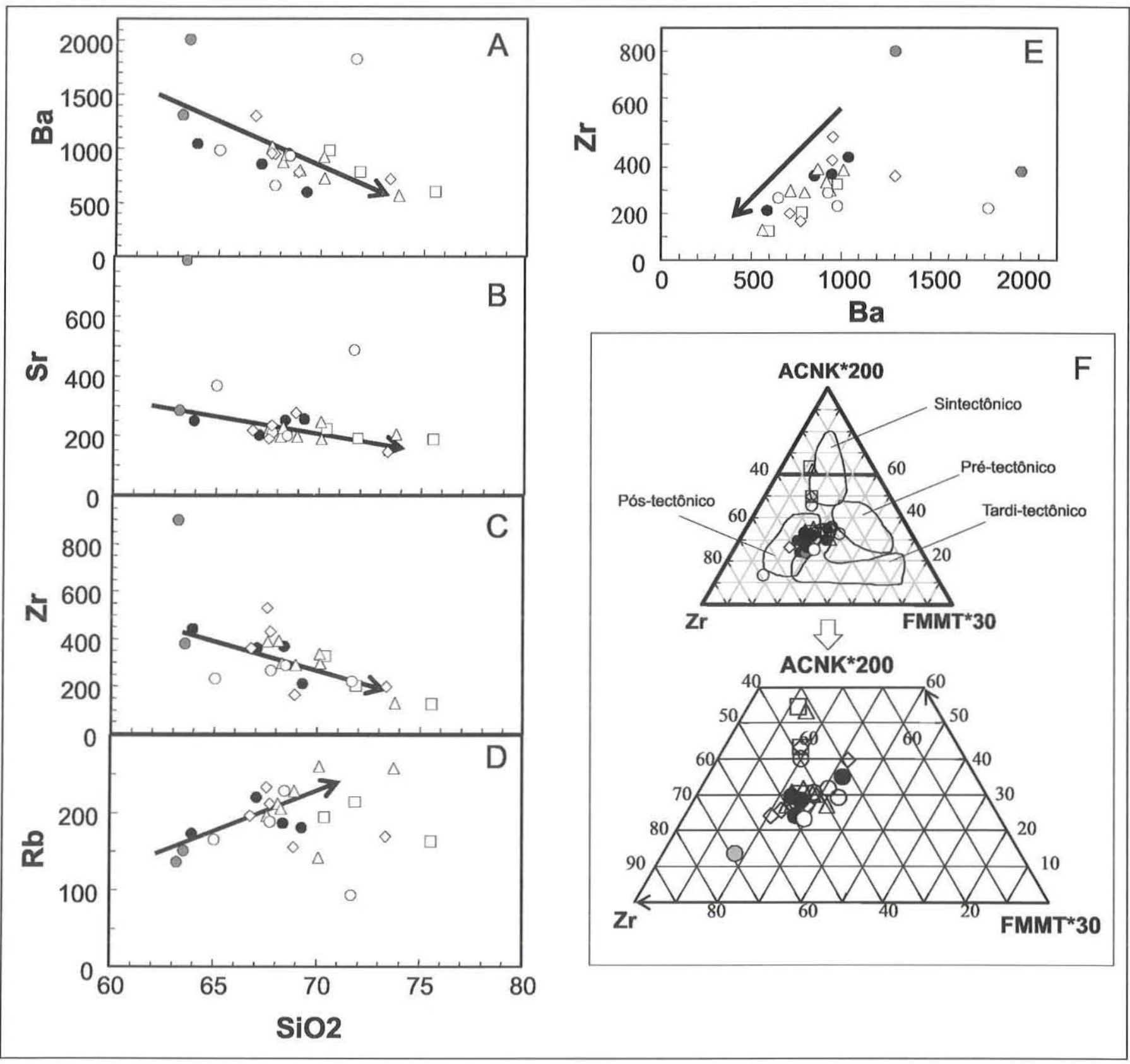

Figura 6. Diagramas de Harker e de caracterização geoquímica para as três fácies do Maciço Arrozal. Simbologia como na figura 5. Legenda: A, B, Ce D-diagramas $\mathrm{SiO}_{2}$ vs. Ba, Sr; Zr e Rb; E- Ba vs. Zr (tendências indicadas por flechas); $\mathrm{F} e \mathrm{G}-\mathrm{diagrama}$ triangular com indice de saturação em alumina (A/CNK*200) vs. $\mathrm{Zr} v s . F M M T * 30\left(\mathrm{Fe}_{2} \mathrm{O}_{3} t+\mathrm{MnO}+\mathrm{MgO}+\mathrm{TiO}\right)$ e a classificação tectônica dos granitos proposta por Bilal et al. (2000) para a região do vale do Rio Doce, $M G$. 
- comportamento da fácies foliada, em relação aos parâmetros de A/CNK, FMMT e o teor em Zr (Fig. 6C), permanece semelhante ao que foi observado nas amostras da fácies porfirítica (comparar com a Fig. 3E), com as amostras ocupando igualmente o campo de granitos tardi a pós-tectônicos da classificação de Bilal et al. (2000), usada para os granitóides neoproterozóicos dos estados do Espírito Santo e Minas Gerais (ver Fig. 6F). O conjunto de amostras desta faciologia distribui-se nos mesmos campos dos diagramas discriminantes das fácies porfirítica e leucogranítica (Figs. 4A e B).

DISCUSSÃO A comparação dos dados geoquímicos do Maciço Arrozal (MA) com os do Maciço Getulândia (MG) (incluindo os dados químicos obtidos por Valladares 1996) mostra semelhanças e diferenças entre eles, que serão discutidas a seguir.

As amostras do Maciço Getulândia (GTG 221 e GTG 222), com teores em $\mathrm{SiO}_{2}$ entre 70,8 a 75,3\%, sugerem corresponder a termos mais evoluídos do que as faciologias do Maciço Arrozal. De acordo com os dados químicos obtidos por Valladares (1996), o MG apresenta teores de $\mathrm{SiO}_{2}$ variável no intervalo de 66 e $74 \%$.

Os demais parâmetros geoquímicos parecem confirmar esta estreita relação entre os maciços para valores idênticos em $\mathrm{SiO}_{2}$ : índice $\mathrm{A} / \mathrm{CNK}$ ligeiramente peraluminoso $(1,16) ; \mathrm{K}_{2} \mathrm{O}>4,0 \%$ (4,3 e 5,6\%), $\mathrm{K}_{2} \mathrm{O} / \mathrm{Na}_{2} \mathrm{O}>1,80$, e conteúdos globais semelhantes em elementos traço, juntamente com as mesmas tendências de correlação negativa para $\mathrm{Ba}, \mathrm{Sr}, \mathrm{Zr}$ com a $\mathrm{SiO}_{2}$, e positiva com o Rb. Os valores de índice de saturação em alumina do MG (entre 1, 0 a 1,01: Valladares 1996) são similares aos valores apresentados pelas fácies porfirítica e foliada do MA, situandose no limite de valores dos granitos tipo-I (entre 0,9 e 1,1 ) e tipoS (entre 1,1 e 1,4) australianos (Chappell \& White 1992).

Os conteúdos em Rb entre 252 e 327 ppm são mais elevados do que das faciologias do MA, cujos valores situam-se no intervalo dos granitos fracionados autralianos (Chappell \& White 1992), reafirmando assim o caráter mais evoluído desse maciço em relação ao MG.

A comparação entre os dados geoquímicos (elementos maiores, menores e traço) do MA com outros maciços similares do estado do Rio de Janeiro (Pedra Branca, Sana, Nova Friburgo e Surui), estudados por vários autores (Junho \& Penha 1985, Junho et al. 1987, 1991 e 1993, Junho 1993), mostra valores similares em $\mathrm{Al}_{2} \mathrm{O}_{3}\left(14\right.$ e $15 \%$ ), levemente superiores em $\mathrm{K}_{2} \mathrm{O}$ (entre 5 e $6 \%$ ), P, Ga, $\mathrm{Zr}$ e Nb, sem uma tendência definida para o Ca, Ni, Zn e Rb (entre 250 e 300 ppm). Por outro lado, nota-se teores muito mais elevados em $\mathrm{CaO}(4$ e $4,5 \%)$ e $\mathrm{Sr}(800 \mathrm{ppm})$, para o Nova Friburgo e, mais baixos, para o Suruí e Sana.

Os granitos do MA, uma vez normalizados segundo os valores dos granitos de dorsais oceânicas (Pearce et al. 1984), apresentam valores de $\mathrm{Ba}_{\text {ORG }}>11$ a $40, \mathrm{Nb}_{\text {ORG }}>1,6$ a $3,3{\text { e } \mathrm{Zr}_{\text {ORG }}>}^{>}$ 0,6 a 2,6, que são superiores aos dos granitóides peraluminosos do cinturão Dom Feliciano $\left(\mathrm{Ba}_{\mathrm{ORG}}<10, \mathrm{Nb}_{\mathrm{ORG}}<2 \mathrm{e} \mathrm{Zr}_{\mathrm{ORG}}<\right.$ $0,5)$ apresentados por Bitencourt \& Nardi (2000). Estes autores, reconhecem quatro grandes grupos de magmas graníticos associados aos cisalhamentos transcorrentes do estágio pós-colisional: (a) granitóides cálcio-alcalinos alto-K; (b) granitóides peraluminosos; (c) granitóides shoshoníticos; e (d) granitóides alcalinos. Todos estes grupos são discriminados entre si com base nas associações de campo, variabilidade de tipos petrográficos e geoquímica de elementos traço.

CONCLUSÕES O comportamento dos elementos maiores e traço selecionados é muito semelhante entre as faciologias dos Maciços Arrozal e Getulândia, sobretudo com as fácies porfirítica e foliada do primeiro, mostrando que o processo de- formacional (no estado sólido) e a interação com a fase fluída não foram suficientes para promover alterações importantes do comportamento químico desses elementos, conforme sugerido pelos diferentes diagramas utilizados.

A comparação entre as duas faciologias (porfiritica e foliada) do Maciço Arrozal permite destacar os seguintes aspectos:

- correlação negativa do $\mathrm{Sr}, \mathrm{Ba}$ e $\mathrm{Zr}$ com a $\mathrm{SiO}_{2}$, refletindo em ambos os casos processos magmáticos relacionados com o fracionamento do plagioclásio e zircão;

- Estabilização e tendência de correlação negativa de K e $\mathrm{Rb}$, a partir dos teores de $\mathrm{SiO}_{2}$ ao redor de $70 \%$, refletem da mesma maneira processos magmáticos relacionados com o fracionamento de feldspato de potássio e biotita;

$$
\text { correlação negativa da soma FMMT }
$$

$\left(\mathrm{Fe}_{2} \mathrm{O}_{3}+\mathrm{MgO}+\mathrm{MnO}+\mathrm{TiO}_{2}\right)$ com a $\mathrm{SiO}_{2}$ é compativel com o fracionamento de minerais ferromagnesianos (sobretudo biotita, ilmenita e magnetita) nas diferentes faciologias;

- a superposição no diagrama de saturação em alumina entre as amostras das fácies porfirítica e foliada, com o índice $\mathrm{A} / \mathrm{CNK}$ entre 1,0 e 1,2, caracteriza este magmatismo como marginalmente peraluminoso. Este índice superpõe-se aos dos granitos pré- $\mathrm{F}_{2}$ (entre 1,05 e 1,2 ) e tardi a pós- $\mathrm{F}_{3}$ (entre 1,1 e 1,17 ) dos granitos neoproterozóicos do estado do Rio de Janeiro (Machado 1997). Além disso, este intervalo de valores situa-se no limite dos granitos tipo-I (entre 0,9 e 1,1) e tipo-S (entre 1,1 e 1,4), caracterizados para os granitos australianos (Chappell \& White 1992);

- a existência de amostras mais enriquecidas em $\mathrm{SiO}_{2}$ na fácies foliada pode ser devido ao aumento deste elemento promovido por uma fase fluída, que acompanhou o processo de deformação no estado subsólido, ou mesmo pela existência de termos mais evoluídos na porção deformada do maciço;

- distribuição dominante das faciologias estudadas no campo de granitos tardi e pós-tectônicos no diagrama apresentado por Bilal et al. (2000), contendo os granitos neoproterozóicos da região do vale do Rio Doce, nos estados do Espírito Santo e Minas Gerais;

Os dados aqui discutidos permitem caracterizar o Maciço Arrozal como relacionado a um magmatismo de composição não-expandida "restricted"(sensu Pitcher 1979: maior proporção de composição granítica, em relação à granodiorítica-tonalítica e gabro-diorítica), tipo-I Caledoniano, de características tardi- a pós-colisional ao Ciclo Brasiliano II, associado ao sistema de cisalhamento de alto ângulo do vale do rio Paraíba do Sul. Trata-se de um corpo com posicionamento tardio ao metamorfismo regional do Cinturão Paraíba do Sul no Estado do Rio de Janeiro.

Este maciço apresenta características geoquímicas comparáveis ao do magmatismo neoproterozóico tardi- a pós-orogênico descrito em outras porções do Cinturão Paraíba do Sul no Rio de Janeiro e Espírito Santo (Junho 1993, Wiedemann 1993, Figueiredo \& Campos Neto 1993, Campos Neto \& Figueiredo 1995, Machado 1997, Bilal et al. 2000).

Apesar da diferença de idade, o magmatismo do MA é também comparável ao dos granitóides cálcio-alcalinos alto-K ou até mesmo shoshoníticos do cinturão Dom Feliciano no Rio Grande do Sul (Lima \& Nardi 1992, Bitencourt \& Nardi 2000, dentre outros).

Agradecimentos Os autores agradecem à FAPESP (Proc. 98/00912-8), pelo suporte financeiro que permitiu a realização das atividades de campo e da parte analítica do trabalho, e ao CNPq (Proc. 300423/82-9, de R. Machado), pela concessão de uma bolsa de Produtividade em Pesquisa. Agradecemos também aos relatores da RBG pelas sugestões ao manuscrito. 
Petrografia e Geoquimica do Maciço Granítico Arrozal: intrusão tardi a pós-colisional associada aO SISTEMA de cisalhamento de alto ângulo do vale do rio Paraiba do Sul, SW do Rio de Janeiro

\section{Referências}

Batchelor R.A. \& Bowden P. 1985. Petrogenetic interpretation of granitoids series using multicationic parameters. Chem. Geol., 48:43-55.

Bilal E., Horn H., Nalini Jr. H. A., Mello F. M., Correia Neves J.M., Giret A., Moutte J., Fuzikawa K., Fernandes M. L. 2000. Neoproterozoic granitoid suites in southeastern Brazil. Rev. Bras. Geoc., $30(1): 51-54$.

Bitencourt M.F. \& Nardi L.N. 2000. Tectonic setting and sources of magmatismo related to the southern Brazilian shear belt. Rev. Bras. Geoc., 30(1,2,3):184-187.

Campos Neto M.C. \& Figueiredo M.C.H. 1995. The Rio Doce orogeny, Southeastern Brazil. J. South Am. Earth Sci., 8: 143-162.

Chappell B.W. \& White J.R. 1992. I- and S-type granites in the Lachlan Fold Belt. Trans. R. Soc. Ed. Earth Sci., 83:1-26.

Figueiredo M.C.H. \& Campos Neto M.C. 1993. Geochemistry of the Rio Doce magmatic arc, Southeastern Brazil. An. Acad. Bras. Ciênc., 65 (Supl. 1):63-81.

Heilbron M. 1993. Evolução Tectônico-metamórfica da seção Bom Jardim de Minas (MG)-Barra do Pirai (RJ). Setor central da Faixa Ribeira. Tese de Doutoramento, Instituto de Geociências, Universidade de São Paulo, São Paulo, 268p.

Heilbron M. 1995. O segmento central da Faixa Ribeira: sintese geológica e ensaio de evolução geotectônica. Tese de Livre Docência, Departamento de Geologia e Geofisica, Universidade Estadual do Rio de Janeiro, Rio de Janeiro, 110p.

Heilbron M., Valeriano C.M., Valladares C.S., Machado N. 1995. A orogênese brasiliana no segmento central da Faixa Ribeira, Brasil. Rev. Bras. Geoc., 25(4):249-266.

Heilbron M., Valeriano C.M., Valladares C.S., Machado N., Almeida, J.C.H., Tupinambá M., Duarte, B.P. 1996. The brasiliano orogeny (590-520 Ma) at the central segment of Ribeira belt, SE Brazil. In: SBG, Congr. Bras. Geol., 39, Camboriú, SC, Anais, 6, p.107-109.

Higgins W. M. 1971. Cataclastic rocks. U.S. Geol. Survey, Prof. Paper, 687, Washington, 77p.

Irvine T.N. \& Baragar W.R.A. 1971. A guide to the chemical classification of the common volcanic rocks. Can. J. Earth Sci., 8:523-548.

Junho M.C.B. 1991. Contribuição à petrologia dos maciços graniticos da Pedra Branca, Frades e Nova Friburgo, Rio de Janeiro. Tese de Doutoramento, Instituto de Geociências, Universidade Federal do Rio de Janeiro, Rio de Janeiro, 198p.

Junho M.C.B. 1993. Granitóides brasilianos da região central do Estado do Rio de Janeiro - geoquímica preliminar. An. Acad. Bras. Ciênc., 65(2):161-179.

Junho M.C.B. 1998. Rochas granitóides do estado do Rio de Janeiro. In: M.J.G. Fonseca (Coord.). Mapa geológico do Estado do Rio de Janeiro, escala I: 400.000. Rio de Janeiro, DNPM/MME, 141p. (Texto Explicativo).

Junho M.C.B. \& Penha H.M. 1985. Geologia e geoquímica dos granitos de Teresópolis, RJ. An. Acad. Bras. Ciênc., 57:546.

Junho M.C.B., Weber-Difenbach K., Wiedemann C., Penha H.M. 1987. Major and minor elements geochemistry of Pedra Branca, Frades and Nova Friburgo granitic complexes, Ribeira Mobile Belt, RJ, Brazil. Rev. Bras. Geoc., 17(4):507-511.

Le Maître R.W. 1989. A classification of igneous rocks and glossary of terms: recommendations of the International Union of Geological-Sciences Subcommmission on the systematics of igneous rocks. Blackwell, Oxford, 193p.
Lima E.F. \& Nardi L.V.S. 1992. O magmatismo shoshonítico no Estado do Rio Grande do Sul. Uma revisão. Pesquisas, 19(2):190-194.

Machado N., Valladares C., Heilbron M., Valeriano C. 1996. U/Pb geochronology of the central Ribeira belt: implications for the evolution of brasiliano orogeny. Prec. Res., 79:347-361.

Machado R. 1997. Litogeoquimica e tectônica dos granitóides neoproterozóicos do Cinturão Paraíba do Sul no Estado do Rio de Janeiro. Tese de Livre-Docência, Instituto de Geociências, Universidade de São Paulo, São Paulo, 215p.

Machado R. \& Dehler N.M. 2002. Revisão e discussão do significado tectônico dos granitóides do tipo-S no estado do Rio de Janeiro. Rev. Bras. Geoc, 32(4):471-480.

Machado R. \& Demange M. 1991. Contexto tectônico e estrutural dos granitóides brasilianos do Estado do Rio de Janeiro. In: SBG/Núcleo SP, Simp. Nac. Est. Tect., 3, Rio Claro-SP, Bol. Res. Exp., p.64-65.

Machado R. \& Demange M. 1992. Granitogênese brasiliana no Estado do Rio de Janeiro: Caracterização geoquímica, modelo tectônico e considerações geológicas sobre o embasamento e a cobertura do cinturão Ribeira na região. In: SBG,/Núcleo SP, Congr. Bras. Geol., 37, São Paulo, Bol. Res. Exp., v. 1, p. 379-380.

Machado R. \& Demange M. 1994. Classificação estrutural e tectônica dos granitóides neoproterozóicos do Cinturão Paraíba do Sul no Estado do Rio de Janeiro. Boletim do IG-USP, 25:81-96

Machado R. \& Pellogia A.U.G. 1987. Mapa de distribuição das rochas granitóides do Estado do Rio de Janeiro: uma avaliação preliminar das informações disponíveis. In: SBG/Núcleo SP, Simp. Reg. Geol., 4, Rio Claro, Atas, v. 1, p. 93-96.

Maniar P.D. \& Piccoli P.M. 1989. Tectonic discrimination of granitoids. Geol. Soc. Am. Bull., 101:635-643.

Nummer A.R. 2001. Geometria e cinemática de alojamento do maciço granítico Arrozal, sudoeste do Estado do Rio de Janeiro. Tese de Doutoramento, Instituto de Geociências, Universidade de São Paulo, São Paulo, 169p.

Pearce J.A., Harris N.B.W., Tinldle A.G. 1984. Trace element discrimination diagrams for the tectonic interpretation of granitic rocks. $J$. Petrol., 25(4):956-983.

Penha H.M. 1984. Granitóides da região central do Estado do Rio de Janeiro: uma síntese dos conhecimentos existentes. In: SBG/Núcleo RJ/ ES, Congr. Bras. Geol., 33, Rio de Janeiro, Anais, 6, p. 2849-2853.

Pitcher W. 1979. Comments the geological environments of granites. In: M.P. Atherton \& J. Tarney (eds.) Origin of granite batholiths geochemical evidenc., Shiva Publishing Ltda, pp.: 1-9.

Streickeisen A. 1976. To each plutonic rocks its proper nome. Earth Sci. Rev., 12:1-33.

Valladares C.S. 1996. Evolução geológica do complexo Paraiba do Sul, no segmento central da Faixa Ribeira, com base em estudos de geoquímica e geocronologia $\mathrm{U}-\mathrm{Pb}$. Tese de Doutoramento, Instituto de Geociências, Universidade de São Paulo, São Paulo, 147p.

Wiedemann C.M. 1993. The evolution of the Paleozoic, late- to postcollisional magmatic arc of the coastal mobile belt, in the state of Espírito Santo, eastern Brazil. An. Acad. Bras. Ciênc., 65 (Supl. 1):163-181.

Manuscrito A1572 Aprovado em 01 de setembro de 2006 